\title{
Mapping Disaster Risk Reduction and Climate Change Adaptation: progress in South Africa
}

\author{
Judith M. Storie ${ }^{\mathrm{a}}$ \\ ${ }^{a}$ Pegasys (Pty) Ltd, South Africa; maryna@pegasys.co.za ; www.pegasys.co.za
}

\begin{abstract}
Disaster Risk Reduction (DRR) and Climate Change Adaptation (CCA) strategies in Africa are on the increase. South Africa is no different, and a number of strategies have seen the light in aid of reducing disaster risk and adapting to cli-mate change. The DRR and CCA processes include the mapping of location and extent of known and potential hazards, vulnerable communities and environments, and opportunities that may exist to manage these risks. However, the mapping of often fast-changing urban and rural spaces in a standardized manner presents challenges that relate to processes, scales of data capture, level of detail recorded, software and compatibility related to data formats and net-works, human resources skills and understanding, as well as differences in approaches to the nature in which the map-ping processes are executed and spatial data is managed. As a result, projects and implementation of strategies that re-late to the use of such data is affected, and the success of activities based on the data may therefore be uncertain. This paper investigates data custodianship and data categories that is processed and managed across South Africa. It explores the process and content management of disaster risk and climate change related information and defines the challenges that exist in terms of governance. The paper also comments on the challenges and potential solutions for the situation as it gives rise to varying degrees of accuracy, effectiveness for use, and applicability of the spatial data available to affect DRR and improve the value of CCA programmes in the region.
\end{abstract}

Keywords: Disaster Risk Reduction, Climate Change Adaptation, Spatial data, Big Data, Data Quality, Data Capture, Data Management, Metadata, Standardization, Availability, Spatial Data Infrastructure, South Africa.

\section{Introduction}

Disaster Risk Reduction (DRR) (based on the Sendai Framework (UNISDR, 2015)) and supported by the Sustainable Development Goals (SDGs) (UN, 2015) has become a key focus of Southern African disaster management activities. Since climate change can be considered a component within the realm of disaster risk, data management and mapping of data and information related to the two fields are inexplicably linked. Therefore, as DRR focus increase, it invariably gives rise to increased emphasis on the development of Climate Change Adaptation (CCA) data and information dissemination and vice versa.

No longer is prevention and mitigation of disaster risk and climate change the main focus of research and policy - the realities associated with disaster events, which include climate related events, is a driver of preparation for and reduction of risk and the implementation of change management. These processes and initiatives are highly dependent on data - both spatial and non-spatial. This paper presents a status quo of some of the key data sets that are freely available via the internet, for public and official use. The paper provides a review of available spatially concomitant data sets and initiatives of DRR and CCA in Southern and in particular South Africa and focus on the potential for application of this data to mapping and data interpretation purposes. Although it may not be fully comprehensive (as such an exercise would require significant additional reporting space), the listing of some of the significant available spatially referenced data, the relevance of the data sets, context of interpretation and application for use, and the custodianship of the selected reported data sets is reported on.

To understand the challenges of proliferation and standardization related to DRR and CCA data, one has to have some concept of the mechanisms that drive data collection and analyses. Not only do agencies funding DRR and CCA work in South Africa compete for avenues of spending, but institutions that engage in research also compete - some-times on their own and sometimes in collaboration - for funds. The result is a vast sea of data and research outputs that all try to outperform one another. This may lead to some confusion, but the positive outcome is that there is a significant amount of information available regarding DRR and CCA.

As digital data volumes worldwide increase, so do the complexities related to its management, interpretation, storage and updating. Although very few of the data sets referred to in this paper are available in real time, the future, especially when considering real time satellite image enablement may present another challenge - that of Big Data. The global importance that geospatial information and services related to disasters and climate change play is recognized through recent developments such as the international Strategic Framework for Geospatial Information and Services for Disas-ters (UNGGIM, 2016) and the Global Framework for Climate Services (World Meteorological Association (WMO), n.d.). Although cloud-based data networks are on the 
increase and some data sets, such as Coordinated Regional Cli-mate Downscaling Experiment (CORDEX) can be downloaded from a variety of servers globally, most data sets hosted by South African institutions are currently stored on singular intranets or at best served via linkage to locally hosted servers. Network speeds and downtime of networks therefore has a significant effect on access to data. The vastness of data types, formats and sources for DRR and CCA is increasing steadily and rapidly from a decade ago, when data was scarce and spatial representation limited (Archer, 2003). As a result of the large amount of stakeholders and data custodians (a list of which is available on the SASDI website (n.d.)) involved it is difficult to control the quality of data sets, and standardize themes and fields that are captured. In addition, challenges arise in ensuring adequate metadata capture and the sharing of raw data as opposed to reportrelated mapped outputs. In particular, copyright restrictions, intellectual property restrictions and confidentiality constraints may lead to non-disclosure of raw data that could sup-port disaster risk and climate change management. The non-disclosure in turn may lead to duplication of data collection and reporting based on differ data sets and source data standards, resulting in disparate reporting bases. Another element that is contested by some is the perceived rift has seemingly emerged between academic research and privately funded projects: although academic outputs may have increased access to a wide variety of raw data, but is often constrained by a lack of financial support and marred by competition to gain academic standing and funding. On the other hand, industry-funded outputs are often supported by fast-paced objectives that have financial backing, but where data purchase processes support selective raw acquisition.

The plethora of seemingly well-researched, well-intended and fairly easily accessible information that support disaster risk reduction and climate change adaptation, is unfortunately not always supported by standardized, readily and freely available raw data. Spatial data in particular displays this characteristic, and this paper thus also explores the legislative environment of the data infrastructure related to base data sets. In addition to regulation of base data set custodianship, the challenge related to spatial data availability is specifically associated with confirming the accuracy and origin of the source data. Ultimately, matching the purpose for which data was originally collated versus what it may be used for in future raises concerns of applicability for decision making processes which it may be used for.

\section{Data structures, types and formats}

There are various data sources and custodians for selected disaster types and DRR and CCA elements. Due to the nature of the data and the custodian hosting the data, no single source of data is accessible to obtain the range of data required to map DRR and CCA. In addition, the use and re-use of data is mainly governed by restrictions set by data custodians and institutions, with no best practice or standard methods in existence to guide access to or re- use of data. To date there is also no single platform able to provide access to the entire range of data that is required to support decision making in a combined fashion - even if the origin data may be distributed across a wide network. Where emergency events are responded to by Emergency Management Services (EMS) (for example when fires occur), the data is often captured at local fire stations and seldom disseminated to disaster management centres at regional or national scale. Similarly, when large-scale disasters occur, data is often captured by regional institutions such as provincial disaster management centres, but not necessarily shared with local services.

Although the South African National Disaster Management Framework (2005) has as one of its enablers the establishment of an Information and Communication System by the primary DRR data custodian - the National Disaster Management Centre (NDMC), this system is yet to be developed (Hoets, 2017). Not only is the limitation related to the extent and size of the data, but also the focus and function of custodians determine their specific area of interest and expertise, that is reflected in their data sources and products. In turn, the data custodians are directly responsible to the funding agencies and mechanisms or partnerships that support the data existence. The result often serves data service providers, as opposed to the users and ultimate mappers of the data.

In particular, where selected data sources, such as environmental base data (vegetation cover, land use and the like) is not considered primary sources for DRR and CCA mapping, but rather play a supporting role (for example as layers underneath hazard or vulnerability data set overlays), the custodianship varies significantly and the levels of accuracy scale and applicability across a wide range of users is questionable. As such, the distributed network of role players applies differing objectives with regard to data collection, capture, analyses and mapping, resulting in often dissimilar implementation and distribution tactics. The situation challenges DRR and CCA since the multidisciplinary nature of these focus areas covers a significantly wide range of disciplines and sectors in society, with both private and public role players involved (Tall, 2017). The situation also calls for a coordinated approach where each role player and data custodian may still focus on their specialist area(s) of expertise, but cooperate in a manner that ultimately benefit the end users of the data or information that they produce.

Some of the data that supports DRR and CCA initiatives is available free of charge while others are not - a function of funding and commercial business models, and governance considerations - as example, the National Register of Disasters in South Africa, hosted by the NDMC, is a restricted database, not available for public consumption (NDMC, n.d.). Despite data scarcity being a challenge (Musango, 2017), a significant amount of raw data is in fact freely avail-able. It is in the accessibility and ease of use where the challenge lies. Freely available data may differ in raw format, standards, scales and even 
projections, making overlay and compilation of composite maps that present multi-disaster risk maps difficult.

Where data is freely available, some raw data formats such as satellite images (which are freely available) that can be used for disaster risk consideration purposes, or data that provide regional climate simulation outputs (such as CORDEX, n.d.) require a high level of technological and software engagement to be applied in its raw format in disaster and climate management. The result is a rift between technical raw data available for map production, and the end-user map-reading audience.

Another type of satellite imagery that could greatly support DRR and CCA comes in the form of interpreted high quality products that often has excellent DRR and CCA applicability. Apart from some data sets that are fairly easy to access (NOAA, n.d.), the size and extent as well as software resources required to utilize satellite image data in general is daunting. A large portion of inferred products and professionally developed data sets that serve the private sector and commercial market (GTI, 2016), some of which come at relatively high financial cost to some role players in the South African market, leaving entities such as Non-Governmental Organizations (NGO's), poorly funded research entities and poor local municipalities unable to afford data that may positively transform their DRR and CCA strategies. The same situation exists with regard to other remote sensing outputs such as Light Detection and Ranging (LiDAR) and even aer-ial photography, although to a lesser extent as outputs age. With regard to both the specially developed interpreted data sets and LiDAR, there is a cost associated with the development of such quality data: if the data is applied correctly and results in a cost saving or an improvement in efficiencies and decision making, then the data costs are mitigated and justified. If the data is used purely for a map, for example, then the data is expensive and the users need to under-stand its value and apply is correctly in support of decision making and operation requirements.

Free digital orthophotos are available at high resolution, across most of South Africa, through the Chief Directorate of National Geospatial Information (CD: NGI). The age of the photos depends on the area - in some cases the currency of the data is less than 6 months. Vector based data is also generally in a good position, with many data sets being fairly easily accessible and freely available. However, with regard to vector data in particular, non-standardization across time and within data themes presents significant challenges. As a result of the above described situation, some disaster and climate data categories and geographical areas are better covered, maintained and updated than others. The sources and origins of data sets differing significantly cause concern when making decisions based on this cross-disciplinary data base.

\section{Regulatory and institutional context}

Transferring scientific data to an audience that may vary in demographics and technical expertise is a challenging prospect. Depending on the user group, the graphics must either portray the information and relevance to the user, who may have a very specific question or interest, in no more than minutes (if not seconds), or it should be providing the data in raw or near-raw format so that users can conduct their own analyses. Since visualizations go a long way to transfer knowledge, it is very important that the maps be accurate. However, the question of accuracy relates to the quality and features of the raw data that the map is produced from. The challenge therefore ends up not being so much a data scarcity when it comes to DRR and CCA data, but challenges related to accessing data, having metadata about the data and its origins and applicability, and enabling readers of the maps compiled or visualizations created from the data, who are more often than not no specialists in a particular field, to a) find what they need, b) timely (for forecasting and after disaster strikes) and c) interpret it accurately.

\subsection{Spatial Data Infrastructure: a good idea, difficult to execute}

Spatial data management in South Africa is regulated through the Spatial Data Infrastructure (SDI) Act (Act 54 of 2003) (South Africa, 2003). The Infrastructure emerged due to the need for standardised access to and management of data sets of national importance. The National Spatial Information Framework (NSIF) in South Africa enables the implementation of South African Spatial Data Infrastructure (SASDI, n.d.). The Framework further enables the Committee on Spatial Information (CSI) in implementation of goals such as establishing an electronic metadata catalogue and determination of standards and prescriptions with regard to the facilitation and sharing of spatial information (NGI, n.d.). Following best international practices, the SDI Act defines the framework within which the SASDI functions. As such, the SDI can be defined as the basic underlying framework, fundamental facilities and systems for spatial data serving the country, and it applies to all spheres of government as well as sectors of society. The SDI intention is noble and the ideal that it strives for is a standardized and ordered form of operation across the country and across sectors, industries and disciplines in the public, private and parastatal sectors. However, the time that it takes to implement hampered the effect the Act may have: an example of delayed implementation is the publication of regulations pertaining the Act, and a draft regulatory document only became available in December 2015.

Although DRR and CCA data falls into the realm of data sets that could be governed through the SDI the question remains as whether it would be considered "base data sets" (CSI, n.d.) within the definition of the custodians and data sets that are directly governed by the Act and regulations or whether it would remain on the fringes of inclusion. In addition, one has to consider how it may be possible (or if it is even feasible) to press the wide variety of custodians of DRR and CCA data into a data infrastructure that is developed after the institutions and data sets have evolved. Both DRR and CCA data that 
informs strategies and decision making requires a wide variety of base data sources and maps.

Whereas SDI supports DRR and CCA data requirements since it strives for 'invisibility', it would also constrain the custodians to operate within limitations that they may not be previously used to. The SDI enables crossplatform and cross-sectoral use of spatial data, for example by defining parameters for:

- Finding relevant spatial data (metadata, catalogues, discovery, and standards that support a specific decision making process);

- Accessing spatial data (with portals, license, costs, standards, etc. being defined); and

- Using spatial data (considering quality, update frequency, standards etc.).

The objectives of the SDI include the establishment of the CSI, establishment of electronic metadata catalogues and/or services; determination of data capture and data management standards, capturing and publishing metadata, and supporting the avoidance of duplication of data capture. Custodians of the SDI can be an organ of state, parastatal, or an independent contractor or person engaged in the exercise of a public service which captures, maintains, man-ages, integrates, distributes or uses spatial information for decision makers and other users. Within the context of the SDI, base datasets are those themes of spatial information which have been captured or collected by a data custodian. Considering this background, the SDI is a key enabler of effective mapping in particular for DRR and CCA. However, there are challenges to the situation.

Other than what is contained in the SDI Act, there is no additional laws governing data standardization and no one institution or governing body that harmonizes data sets as sectors and disciplines. Although there is also no driving agency that oversees the enforcement standards such as ISO TC211, In terms of the SDI Act, data custodians are required to comply with standards as listed by the Minister. At the time of this paper being written, such list has not been published - it is a work in progress. Apart from the practicalities noted earlier and related mainly to cost, the baseline from which the SDI is implemented is significantly fragmented. No matter how much effort is expended to reduce du-plication, it seems a futile effort to eliminate replicas of data sets - for example road, water body, river centerline and wetland vector data although available freely, exist in different scales, at differing quality, with differing attributes at different spheres of government. When producing maps using these data sets one either have to choose one or the other data set (and in the process omit potentially relevant information); combine data and merge polygons or hide features that may seem to display as duplicates, but differing boundaries or positioning, or even purchase or produce a new "more accurate" data set that may be considered available. The result is a mass of generally non-standardized DRR and CCA spatial outputs nationwide, with challenges in determining detailed metadata. In turn, the situation poses the concern that interpretation of visualizations and maps that are made using the data sets may either be rejected outright by users, or questioned to various extents.

The latest South African initiative towards integration of CCA data, which invariably affect DRR data, is the National Framework for Climate Services (NFCS), currently motivated by the National Department of Environmental Affairs (DEA). The NFCS aim at providing a User Interface Platform (UIP), Climate Services Information System (CSIS), observations and monitoring, research, modelling and prediction, and capacity development. Underlying the NFCS re-mains significant data but lack of co-ordination of data service providers (Tall, 2017) and lack of standardization (Mbanjwa, 2017). Although the current gap thus has been identified, the NFCS faces the difficult task of increasing co-ordination and standardizing data services in a political environment where even the placement of the Framework within the country's governing structure is uncertain.

\subsection{Regulatory support}

In support of the SDI Act, the environmental, disaster and climate related regulatory environment in South Africa tends to be well-covered, with multiple legal, policy and guideline documents available at the national, provincial and local spheres, enabling and supporting decision making processes aimed at reducing disaster risk and supporting CCA. Unfortunately, the proliferation of these Acts, policies, regulations, guideline documents and rules pertaining different industry sectors tend to hamper the ability of project managers and implementers to ensure that all the angles of approach and regulatory requirements are covered when executing a given project. This regulatory propagation along with the proliferation of issues that are in some cases contradictory across industry sectors require increased coordination and harmonization which would decrease regulatory (and ultimately data-) cross-referencing challenges. Since one Act of guideline may differ from or even challenge another, either within a sector or industry or across sectors/industries, the average DRR or CCA officer or practitioner finds it challenging to identify the appropriate approach towards addressing trans-disciplinary issues and clearly define the data requirements related to their specific area or sector of interest. An example of the challenges associated with such proliferation and differences in local by-law ap-plication in particular is the implementation of the Spatial Planning and Land Use Management Act (also referred to as SPLUMA) (South Africa, 2013). As example, SPLUMA aims to provide an ideal and single land use management protocol nationwide in South Africa. However, the amalgamation of multiple historical and spatially diverse land use management protocols and processes, standards and mapping methods is causing the implementation of this well-intended Act to be significantly delayed. This example is one of many that underpin the spatial data management and mapping challenges associated with DRR and CCA in the country. If these underpinning 
policies and the foundation of data capture and standardization as well as cross-platform operability of raw data can be addressed, potentially via a SDI, many of the challenges associated with mapping could potentially be reduced. In addition, the availability of metadata and the mere knowledge of the existence of certain data sets and initiatives related to DRR and CCA may already have a positive impact on coordination, cooperation and the use of such data for visualization and mapping purposes.

\subsection{Accessibility}

\subsubsection{Stakeholders and custodians}

As alluded to earlier, the volumes of data available from multiple custodians and stakeholders raise the question whether there is indeed significant data scarcity when it comes to DRR and CCA data. Considering the significant amount of data, it is inevitable to come to the conclusion that a large amount of data actually exist, in one form or another. At further introspection it seems to be the metadata component that is lacking, and the availability/distribution of this metadata. With no single institution having responsibility for collating and making available all the metadata data, accessibility of the metadata (in addition to the actual data sets) is a challenge. In addition, challenges related to access to raw data (whether free or at cost) is often a driving force behind the generation of additional or new data: it is often considered easier to embark on new data collection and pilot studies, rather than going through a processes of accessing raw data.

Another challenge relates to the proliferation of research data that is project-based and fund-driven. Whilst funding mechanisms enables data creation, it also generates copious amounts of new data, and instead of collaborating, institutions or partnerships compete to gain access to available budget to further their specific data collection needs (Wat-kiss, 2017). The result include a magnitude of pilot-scale studies that produce nonstandardized data in a variety of formats and at scales that restricts scalability of the data.

To understand the manner in which data management for DRR and CCA in South Africa functions, one need to first understand the three-tier system of government and independent judiciary. The three spheres of government national, provincial and local, all have legislative and executive authority in their own spheres, and are defined in the South African Constitution as "distinctive, interdependent and interrelated" (South Africa Government, n.d.). An argument recently emerged that the government actually has five tiers, where the local tier is in fact divided into a) large urban and significantly independent Metropolitan municipalities, b) district and c) local municipalities - the latter two sometimes underresourced. Although this spherical approach is intended to enable effective democracy, it presents challenges for effective DRR and CCA data management.

South African spatial data that support DRR and CCA projects and processes lie with national government departments such as:
- Department of Water and Sanitation (DWS), hosting on their website the National Integrated Water Information System (NIWIS). Online video-based explanations on how to use and interpret the information are provided, enabling the data to be interpreted more accurately (DWS, n.d.). This data on drought status and management of water resources enables interpretation of, for example dam levels and trends, rainfall trends, drought reports, alerts, warnings and mitigation - free of charge.

- Department of Science and Technology (DST) has funded the creation of the South Africa Risk and Vulnerability Atlas (SARVA) - an atlas of risk and vulnerability within a global change context (DST, 2010). The Atlas provides national, provincial, and municipal-level information relating to aspects such as surface and ground water, forests, biodiversity, air quality/emissions, human health and agriculture as well as social, economic and institutional dimensions (Davis, 2011). Apart from hard copy format, the atlas is also available through an electronic online geospatial database portal (DST, 2010b);

- Department of Environmental Affairs (DEA) at a national sphere, apart from being the drivers of the NFCS mentioned earlier, hosting their Environment GIS (EGIS), which provide "baseline geospatial data and services to users of geospatial technology". Data sets include for example the Protected areas database, National land cover 2013/2014, Renewable energy EIA application database (indicating renewable energy applications in process) and the unpublished draft REDZ dataset, which provide Wind and Solar PV Energy Strategic Environmental Assessments (DEA, n.d.); and

- Department of Agriculture, Forestry and Fisheries (DAFF).

Provincially, data may be curated by departments such as Gauteng Department of Agriculture and Rural Development (GDARD, n.d.), focusing on, among others, "story telling with maps" and including data related to biodiversity, nature conservation, air quality and waste management, as well as agriculture, for example, covering red locusts and fall army worm infestations in crops. In the Western Cape Province, the Smart Agriculture for Climate Resilience (SmartAgri) project was a collaborative project between the Western Cape Department of Agriculture (DOA) and the Western Cape Department of Environmental Affairs and Development Planning (DEA\&DP), and the University of Cape Town's African Climate and Development Initiative (ACDI) (GreenAgri, n.d.). SmartAgri has provided a road map for actionable and prioritised initiatives (including spatial mapping) that will take the agricultural sector road towards greater resilience in the face of climate challenges. The project has also resulted in several resources for the 
agricultural sector including but not limited to digital spatial data related to a plan for each of the agriclimatic zones identified in the Western Cape. In addition, case studies are also freely available online, for example one entitled "Disaster Risk Reduction and Management: the need for joint systematic planning and proactive reduction of extreme weather risks". SmartAgri is an excellent example of the downscaling and application of climate change information to local levels, along with the provision of usable text and spatial data.

At a local sphere, municipalities tend to curate their own data, which may or may not include full-blown online Geo-graphic Information System (GIS) systems (predominantly at Metropolitan Municipalities), locally based GIS (man-aged and available via manual data transfer practices within the district or local municipality), or in some cases very lit-tle or no GIS data or capacity at all. These municipal systems may have any range of GIS data and management pro-cesses related to DRR and CCA - from none at all, to extensive early warning and response systems. The localization of these services challenges regional, provincial and national data integration and especially mapping efforts.

Data management related to disaster risk management poses a challenge. Hosted under the Department of Cooperative Governance and Traditional Affairs (CoGTA), the National Disaster Management Centre (NDMC, n.d.) engages with DRR data at National sphere. The NDMC (according to the National Disaster Management Framework (NDMF) (South Africa, 2005)) is responsible for developing and implementing an integrated Information and Communication System to standardize the collection, analysis, storing and communication of data and information relating to DRR. However, to date and at the time of this paper being compiled, this has not yet been done. As a result, all spheres of government are making use of fragmented, non-standardized data. The fragmented activities of especially local and district municipalities throughout the country to put information together for disaster risk maps often serves little purpose other than to generate a report with associated maps in response to the regulatory demand made through the National Disaster Management Act (South Africa, 2002). Data used across time and space therefore varies significantly, can seldom be applied across municipal and provincial borders in an integrated manner, and often fail to inform decision making (Hoets, 2017). GIS data sets that are available from the NDMC include the National Fire Danger Index, a Flash Flood Guidance System (FFGS) and an Integrated National Early Warning System (INEWS) (ibid). Some of the portals, such as the FFGS, still displayed the status: UnderConstruction at the time that this paper was written, although in reality the data is available within the NDMC (NDMC FFGS, n.d.). The vehicle for dissemination has been a challenge in the recent past, but finally been identified and prioritized for 2017/18 (van Staden, 2017). On a regional and local scale, Provincial DMC's focus on Provincial, and Municipal DMS's on local disaster risk management data. An example of a regional and relatively extensive system is that of the Western Cape Disaster Management Centre (WCDMC, n.d.), including a GIS containing base data such as the location and detail of critical infrastructure, hospitals, schools, high risk areas prone to floods and fires, and it assists with plotting of incidents or disasters. Unfortunately, due to the threetiered nature of government in South Africa discussed earlier, there is little direct link between local, provincial and the national DRR data management efforts. An example of the disparity that exists between governance spheres and project deliverables is prominent in spatial floodlines or flood hot spot data sets: the data that determines flood extents and related risks are distributed across databases hosted by primarily private engineering and hydrological consulting firms. Governing entities that are the receivers of these projects rarely have access to the raw data, and sometimes do not even obtain the digital spatial data that indicate the floodlines, and there is also no standardized process in place to guide the collection, collation and transfer of the available raw data or indicative flood lines and flood danger zones.

Once DRR data management is addressed through the required Information and Communication System, the sys-tem should enable all four key performance areas of the NDMF, more specifically the need for dynamic risk profiling (Hoets, 2017). The Information and Communication System would furthermore significantly improve the quality and quantity of data available for accurate and effective risk assessments, and potentially reduce the costs that are currently associated with spatial data collection, every time that a disaster risk assessment is executed. Currently, the dis-aster risk assessment results are only reviewed once a year when each sphere of government or each department involved is required to review their Disaster Management Plan. As a result, mapping as an outcome of such a risk assessment is only a snap shot of the reality during the time period when the assessment was conducted (ibid). Dynamic risk profiling, instead, would enable near real time interpretation but requires access to standardized, high quality data to constantly inform the risk profile. At the same time, such dynamic risk profiling would enable effective monitoring and evaluation both temporal and spatial, and not only as is currently the case, focus on priority risks (ibid). The result would be a significant improvement in the impact of the projects identified to prevent or mitigate disaster risks.

Other data custodians, each with its own institutional mandate and gatekeeping processes (Watkiss, 2017) include (in no particular order):

- South African National Space Agency (SANSA, n.d.) Earth Observation in the form of raw satellite imagery (for example LANDSAT or MODIS), and some of which is available in near real time;

- South African Environmental Observation Network (SAEON), within the National Research Foundation (NRF, n.d.), constituting a science network of people, organizations and 
observation platforms that perform Long-Term Ecological Research (LTER) (SAEON, n.d.);

- South African Weather Services (SAWS) in the form of for example daily statistics georeferenced to specific weather stations and real time satellite and radar imagery - with some data being freely available while other data sets, services or products are commercially sold (SAWS, n.d.);

- Council for Scientific and Industrial Research (CSIR) units including but not limited to Natural Resources and the Environment: Climate Studies, Modelling and Environmental Health, where significant research is conducted into a wide range of environmental, disaster related and climate change matters, for example, studies on fire occurrences, response time to fire events, drought and fire incidence and the relationship it has with alien vegetation species occurrence and inundation and flooding of coastal regions (Davis, 2017). The Advanced Fire In-formation System (AFIS, n.d.) is a wildfire monitoring and visualization system that provides for near real time fire detection, monitoring, alerting, planning and reporting by making use of observation satellites and weather forecast models (wind speed, temperature, humidity). AFIS, developed and maintained by the Earth Observations Application division of the Meraka Institute of the CSIR, has an online GIS component which can be used to visualize and analyze historical and current fire patterns. It is available free of charge and anyone with an internet connection can access it. The AFIS mobile application is designed for fire managers to assist with fire detection, prediction and historical and current data for areas of interest and is one of the foremost data and mapping bases for fire risk data in South Africa. The system also includes weather forecasts and vegetation conditions. Other data includes statistical data of burnt area estimates per administration boundary or area of interest, merging burnt area estimations and other available data together with all information related to fire statistics and methods used to reduce fire risks nationwide and across different scales and spheres (for example nationwide, regionally and locally);

- South African Water Research Commission (WRC, n.d.), providing, for example, regional water statistics (including free water software), information related to water resources use and the food-water security intersection and access to a drought-specific portal (Drought SA, n.d.);

- International Water Management Institute (IWMI, n.d.) Southern Africa, conducting research of water management in agriculture, irrigation, groundwater, river basins, wetlands, ecosystems, food security, wastewater, etc. (for example crop insurance and flood mapping);

- Agricultural Research Council (ARC), a science institution that conducts research to support the agricultural sec-tor (ARC, n.d.);

- AgriSA, an agricultural industry association (AgriSA, n.d.);

- South African National Biodiversity Institute (SANBI, n.d.a). (SANBI, n.d.a). They provide a range of freely available Atlases recording species distribution, and Infobases including a land degradation report (SANBI, n.d.b) and vegetation maps that indicate changes over time between e.g. 1936, 1953 and 1996 (SANBI, 2017). Their Biodiversity GIS (BGIS) (SANBI, n.d.c) is a key feature providing downloadable spatial information as well as interactive online mapping to a wide range of stakeholders in the DRR and CCA arena; and

- Although institutions such as the Chief Directorate National Geospatial Information (CD: NGI), and Statistics South Africa (StatsSA) maintain base data sets that can be used as supporting base layers to DRR and CCA maps and visualizations, their responsibility pertains primarily to administrative, census and governance related data sets. As such their role is not to provide input into DRR and CCA spatial data sets. However, the availability of data sets such as elevation data and river centerlines from CD: NGI, and Demographics, from StatsSA, invariably supports DRR and CCA related mapping.

The tertiary education sector and institutions associated with tertiary education (with or without government or private support) is another significant role player when it comes to data generation that supports DRR and CCA. There are a wide range of institutes and units that specialize in research related to specific elements of DRR and CCA - potentially competing for research funding and thus producing data sets that may be publically accessible: the largest proportion of these data sets remains restricted to educational and academic use or is only shared with government entities - not with the private sector. In this sector, challenges remain not only related to data standardization, but access to raw data that may support DRR and CCA initiatives, since the research outputs are often published in results-based format only (e.g. in the form of papers, books, or book chapters), thus making access to raw data challenging, or associated with intellectual property constraints. Competition for student numbers and highly qualified staff able to generate research funding increase their reluctance to share selected data resources. The list contains by no means a complete overview and is presented in no particular order, but serves to provide an indication of the vast range of role players involved (remembering that each of these initiatives generate significant volumes of raw and manipulated/modelled geocoded and non-spatial data and 
research outcomes, directly and indirectly related to DRR and CCA across Africa):

- African Centre for Disaster Studies (ACDS) (North-West University, n.d.);

- African Climate and Development Initiative (ACDI) (University of Cape Town (UCT), n.d.);

- Adaptation at Scale in Semi-Arid Areas (ASSAR), aiming to better prepare communities and governments of semi-arid regions in Africa and Asia for the potential impacts of climate change (UCT, n.d.);

- Climate Systems Analysis Group (CSAG) at UCT, and their online and freely accessible Climate Information Platform: CIP (CSAG, n.d.);

- Disaster Management Training and Education Centre for Africa (DiMTEC) (University of the Free State, n.d.);

- The multi-partnership Natural Hazard Centre, Africa (formerly the Aon Benfield Natural Hazard Centre, Africa) (University of Pretoria, n.d.);

- Energy Research Centre (ERC, n.d.) at UCT;

- Global Change and Sustainability Research Institute (GCSRI), a transdisciplinary research institute focusing as an enabling research platform fostering adaptation and innovation in Southern Africa (at the University of the Witwatersrand, Johannesburg) (GCSRI, n.d.);

- Urban Modelling and Metabolism Assessment (uMama) (a Research Group within the Stellenbosch University School of Public Leadership: Centre for Complex Systems in Transitions (CST) (University Stellenbosch, n.d.));

- Periperi U (Partners Enhancing Resilience for People Exposed to Risks) - an Africa continentwide initiative (University Stellenbosch, 2016); and

- Research Alliance for Disaster Risk Reduction (RADAR), also at Stellenbosch University.

In addition to the range of custodians and stakeholders involved and the spatial data in particular that they curate, interpret and map, a wide range of role players in the private sector are also engaged in projects and strategies that assist the predominantly corporate and commercial sector to adapt to disaster risks and climate change challenges. In addition to projects and strategies, a number of the custodians listed above also services related to data interpretation, although many tomes as commercial outputs. An example is the engineering and environmental consulting industry, operating largely on tender-based research and project outcomes. The results of these projects may or may not be available through the funding agents, depending on the nature and purpose of the project. Another role player handling data for visualization of DRR and CCA that is in most cases held closely guarded is the insurance industry, where de-tailed investigations are done in areas and key sectors where DRR and CCA is considered necessary for purely commercial purposes. An example of such studies include investigation into and mapping of drought in relation to impacts on agricultural production, and fires and flooding which impact specific urban areas (Davis, 2017).

\subsubsection{Initiatives designed for regional impact}

There are a number of well-intended initiatives that are supported by significant academic knowledge and research, and enabled by strong financial backing. Following initiatives such as the Southern African Development Community (SADC) Programme on Science and Technology Support for Climate Change Response (Davis, 2011), SADC member states indicated access to climate change information projections and impact studies to be a priority (ibid). The South-ern African Regional Climate Outlook Forum (SARCOF) also complemented the processes (ibid). Other projects include US-AID funded projects for example in the CSIR's Climate Studies, Modelling and Environmental Health Research Group, UK-AID and DFID funding, and a range of similar initiatives involving global funding agencies.

Around the same time, the Southern African Science Service Centre for Climate Change and Adapted Land Use (SASSCAL) was initiated. SASSCAL is a joint initiative of Angola, Botswana, Namibia, South Africa, Zambia, and Germany, responding to the challenges of global change and is foreseen as the regional driver for innovation and knowledge exchange to enhance adaptive land use and sustainable economic development in Southern Africa under global change conditions (Mück, 2013). Sectors covered by the initiative include water, forestry, agriculture, climate and biodiversity. The project mission is to conduct problem-oriented research in the area of adaptation to climate and change and sustainable land management and provide evidence-based advice for all decision-makers and stakeholders to improve the livelihoods of people in the region and to contribute to the creation of an African knowledge-based society (ibid). A crowdsourcing platform was launched in $2016-$ to course local rain data, there individuals or organizations can add their own records (SASSCAL Rain App, 2016.). Most of the outputs of the initiative is either represented in mapped format, or can be used to present visualisations and mapping that related to DRR and CCA, and given the sectors covered by the initiative the custodianship of data sets raises a concern. For example, SASSCAL's Weathernet site provide free data for example for hourly, daily and monthly weather, 10-day rainfall summaries, daily and monthly temperatureprecipitation diagrams, and daily and monthly relative air humidity, clouds, rain rates and streams (SASSCAL Weathernet, n.d.), but not forecasts. Wind speed information is potentially available, but was not readily at 
the time that this paper was written. The weather stations include those stations that SASSCAL manages, and in South Africa that means 11 stations in the West coast of the country. Comparing this to similar information as well as weather forecasts that are provided by SAWS, based on weather monitoring stations across South Africa, the format is not directly translatable between the two systems. SAWS services are also not all free of charge - for example aviation-related services are available only as a commercial product. In addition, the overlaying of the data across spatial geoinformation platforms in a seamless manner is not currently an option. This results in data that is a) not easily spatially represented in a map format and b) that is not standardized to similar field parameters, which officials of disaster risk reduction offices can interpret and utilize.

\section{Pathways of intervention}

The benefit of SDI implementation and standardization of scale and attributes captured across data sets and across disciplines, that influence DRR and CCA is an ideal to be strived for. Realizing that this is a timeous process that may never be a true and final reality, the mere move towards reduction of duplication and establishment of clear metadata and attribute standards would be a significant improvement in the situation that South Africa currently faces. The challenge of data sharing, especially in its raw form, and the enablement of such data across industry sectors and government spheres also requires much-needed attention, although it should be recognized that profit-driven spatial data management and mapping remains present. Processes of enabling data that is currently housed on various platforms and in different formats are in place to support collation, cross-sectoral analyses and sharing, however the usability of some of these information management systems require attention. Although it is currently significantly challenging to create maps that constitute the totality and variety of information that is available across multiple custodian plat-forms, the opportunity does exist to transform this knowledge into DRR and CCA decision support products: both in the form of new data models (for example providing standardized hazard and vulnerability delineations at municipal or community scale countrywide) as well as products and services. The maps resulting from the mentioned activities and initiatives, along with improved collaboration between data custodians and stakeholders in DRR and CCA realm would support not only strategic infrastructure development and maintenance, but also as improved actions for DRR and CCA.

Strategically, it is imperative that resources be channeled towards standardization of the data infrastructure that impacts DRR and CCA mapping. Although South Africa often leads the African continent in the use of data and metadata, much more could be done with great benefit of the country and the continent. The key to the future enablement of effective DRR and CCA lies within initiatives mentioned in this paper, including the sharing of spatial data across government spheres, private industries, parastatals and academic research platforms, for the benefit of society at large.

The challenge remains as to how to overlay or merge the significantly important and widely available data sets to interpret the information for purposes of increasing spatial resilience. One possibility is to apply a service oriented architecture proposed by the Group on Earth Observations (GEO), also in other countries (Lovison, 2016). The amount of effort that is currently required to collect and collate the data, format it and overlay it remains significant, and in many cases the mere obtaining of the data (even if available free of charge) is challenging. Issues of size of data sets (for ex-ample the CORDEX data which is virtually impossible to download without significant network capacity) and then formatting and interpreting the data (again CORDEX as example, where only users with experience in Linux and the unique coding language associated with the product, can interrogate the raw data) also remains.

Considering the lists of data custodians provided in this paper is not comprehensive and that there is a range of additional potential role players that can be added, it strengthens the debate that it is not really a lack of data, but rather a lack of standardization, scale of applicability, cross-platform integration and awareness that is a challenge. While all the mentioned data service institutions exist, the question remains how the fragmented environment can be integrated (Mbanjwa, 2017). In this regard, there is a need for a more comprehensive and coordinated approach for both South and Southern Africa. Addressing the challenge will require a process of significant effort. In essence, the process does not necessarily need more resources, but rather to optimize the resources already in play (ibid). Such a systematic co-ordinated approach will involve coordination at community organization structures, local, regional/provincial and national level, resulting in a collaborative, multi-sectoral approach to visualizing and mapping DRR and CCA.

While the gap between the users and providers of data is still apparent, opportunities exist to utilize policies, Acts, regulations and guidelines as mobilisers and enablers of the process of optimization and integration of data availability versus information needs. Despite large leaps forward there is still significant way to go to go towards enabling effective integration of data (Haak, 2017), and the challenge exists to transfer this information from info into practice.

There may never be a single source, data collection or mapping or visualization tool that can be applied to gain a single perspective on DRR and CCA. This is partly due to the multi-disciplinary nature and complexities of these fields of research, investigation and management. However, by applying a service based architecture of data and metadata, through standard interfaces, it may be possible to allow the development of newer data and metadata over time, within each agency, and sharing 
them for purposes of planning, prevention, risk reduction, adaptation and response when dis-aster strikes. Besides the implementation of such architecture, DRR and CCA mapping efforts face the challenge of a need for standardization as well as making the data widely available to the general public, in a consistent manner that consider changes and updates to policies over time, to promote firm and positive action towards reducing disaster risk and adapting to the changes that the country and the world at large faces. One possible solution to the challenges dis-cussed in this paper is the establishment of standardized pathways of intervention. Regulated or at least guided path-ways and processes would significantly assist in the availability and application of metadata that differentiate data, and processes related to data capture and collection in terms of national, regional and local scales. Over and above ac-cess to the actual datasets, relevant metadata needs to be provided defining information content, data classifications, lineage, data capture methodologies or processes and defines applicable application scales (i.e. national, provincial, metropolitan, district and local municipality) (Martin, 2017). In addition, the creation of systematic mapping themes, where certain standards apply to certain scales of representation would go a long way to enable more effective and ac-curate map interpretation by non-GIS users. The development of data capture methodologies, minimum information content and spatial data classification standards would facilitate the integration of both systematics mapping projects and project driven mapping exercises to provide a continually (operationally) updated dataset. Various government entities have legislative requirements to provide information in response to data custodianship requirements and man-dated performance scorecards and being able to integrate these continuously updated datasets (thematic layers) into a national dataset would provide access to up-to-date and relevant information (ibid). As Cullinan and Kvalsig (n.d.) noted: the shift in the nature of regulations and laws places greater emphasis on the importance of integration of principles, procedures and planning processes. No longer can institutions embark on singular and un-coordinated initiatives without having a clear interaction and communication strategy with role players that are either custodians of data themselves, or would be affected by the data resulting from an initiative.

\section{Acknowledgements}

I am grateful to the following persons for providing support and encouragement into research related to this paper, and assistance with comments into and review that improved manuscripts:

- Prof. S. Coetzee, Department of Geography, Geoinformatics and Meteorology, University of Pretoria, South Africa;

- Prof. J Musango, School of Public Leadership, University Stellenbosch, South Africa;

- Prof. S. Midgley, Project Manager, ACDI, University of Cape Town; Associate Professor
(Extraordinary), Department Horticultural Science, Stellenbosch University.

- Dr. Lucia Lovison-Golob, Geospatial Director, Afriterra Foundation, and Sat Drones;

- Dr. D. Clarke, Chief Director: National GeoSpatial Information (South Africa's National Mapping Organisation); National Department of Rural Development and Land Reform;

- Ms F. Hoets, Disaster Management Solutions (Pty) Ltd;

- Ms S. Reddy, Pegasys (Pty) Ltd;

- Mr S. Martin, Director: Business Development; GeoTerraImage (Pty) Ltd;

- Ms P. Tizora, Department of Geography, Geoinformatics and Meteorology, University of Pretoria, South Africa;

- Ms Y. Bevis, GIS Specialist: ESRI South Africa;

- Mr M. van Staden, GIS Manager, South African National Disaster Management Centre; and

- Ms L du Toit, L. du Toit GIS Services.

The presentation of this paper at the International Cartographic Conference in Washington DC in 2017 is funded by the Afriterra Foundation.

\section{References}

AFIS. (n.d.). AFIS home page. Available at: http://www.afis.co./za Accessed on 27 February 2017.

AgriSA. (n.d.). AgriSA home page. Available at: http://www.agrisa.co.za Accessed on 28 February 2017.

ARC. (n.d.). ARC Home page. Available at: http://www.acr.agric.za Accessed on 28 February 2017.

Archer, E. (2003). Identifying underserved end-user groups in the provision of climate information. Bulletin of the American Meteoro-logical Society, 84(11), 1525 1532 .

CORDEX. (n.d.). Cordex home page. Available at: http://www.cordex.org Accessed on 27 February 2017.

CSAG. (n.d.). CSAG home page. Available at: http://www.csag.uct.ac.za Accessed on 27 February 2017

CSI. (n.d.). Base Dataset Custodian Policy. Government of South Africa: Committee for Spatial Information.

Cullinan, C. and Kvalsvig, S. (n.d.). From Environmental Law to Governance for Sustainability: Experiences in Developing Sustainable Development Legislation for the Western Cape. EnAct International: Governance for a sustainable future. Available at: http://www/puk.ac.za Accessed on 27 February 2017.

DAFF. (n.d.). Provincial Departments of Agriculture home page. Available at http://www.daff.gov.za Accessed on 27 February 2017.

Davis, C.L. (2011). Climate Risk and Vulnerability: A Handbook for Southern Africa. Council for Scientific and Industrial Research. Pretoria, South Africa. P92. 
Davis, C.L. (2017). Presentation as part of short course: Regional Climate Change Assessment and Impact Analysis. CSIR. Stellen-bosch. 20-24 February 2017.

Davies, H. (2017). Session presentation. ICCS5: Innovation in Climate Services and Capacity Building. 28 February to 2 March 2017. Lagoon Beach Hotel, Milnerton, Cape Town.

DEA. (n.d.). EGIS home page. Available at: http://www.environment.gov.za Accessed on 27 February 2017.

DEA. (2010). South African National Climate Change Response Green Paper. Available at: https://www.environment.gov.za/sites/default/files/legis lations/national_climatechnage_response.pdf Accessed on 30 August 2015. Department of Environmental Affairs.

DME. (2003). White Paper on Renewable Energy Policy of the Republic of South Africa. http://www.gov.za/sites/www.gov.za/files/26169_1.pdf Accessed on 15 September 2015. Department of Minerals and Energy.

DME. (2005). Energy Efficiency Strategy of the Republic of South Africa. http://www.energy.gov.za/files/esources/electricity/ee_s trategy_05.pdf Accessed on 20 September $20 \overline{15}$. Department of Minerals and Energy.

DoE. (2008). Government Notice: National Energy Act, 2008. (Act No 34 of 2008). Republic of South Africa. http://www.energy.gov.za/files/policies/NationalEnergy Act_34of2008.pdf Accessed on 1 October 2015. Department of Energy.

DRDLR. (2013a). Climate Change Risk and Vulnerability Assessment for Rural Human Settlements. Department of Rural Development and Land Reform.

DRDLR. (2013b). Climate Change Adaptation Sector Strategy for Rural Human Settlements. Department of Rural Development and Land Reform.

DRDLR. (2015). Regulations made in terms of the Spatial Data Infrastructure Act, 2003 (Act No 54 of 2003). Department of Rural Development and Land Reform.

Drought SA. (n.d.). Drought SA home page. Available at: http://www.droughtsa.org.za Accessed on 27 February 2017.

DST. (2010a). South African Risk and Vulnerability Atlas. Available at: http://www.rvatlas.org. Eds: Archer, E., Engelbrecht, F., Landman, W. et al. Accessed on 26 February 2017.

DST. (2010b). SARVA geospatial database. Available at: http://ravaqsens.net Accessed on 26 February 2017.

DWS. (n.d.). DWS NIWIS home page. Available at: http://www.niwis.dws.gov.za/niwis2/SurfaceWaterStora ge Accessed on 26 February 2017.

ERC. (n.d.). ERC Home page. Available at: http://www.erc.uct.ac.za/ Accessed on 3 March 2017.
GCSRI. (n.d.). GCSRI home page. Available at: http://www.wits.ac.za Accessed on 15 February 2015.

GDARD. (n.d.). GDARD home page. Available at: http://www.gdard.gpg.gov.za Accessed on 27 February 2017.

Gauteng Provincial Government (GPG). (2011/12). Gauteng Green Economy Policy. Gauteng.

Green Agri (n.d.). Green Agri home page. Available at: http://www.greenagri.org.za/smartagri-2/about/ Accessed on 8 March 2017.

GTI. (2016). GeoTeraImage (Pty) Ltd home page. Available at: http://www.geoterraimage.com Accessed on 27 February 2017.

Haak, R. (2017). Keynote presentation. ICCS5: Innovation in Climate Services and Capacity Building. 28 February to 2 March 2017. Lagoon Beach Hotel, Milnerton, Cape Town.

Hoets, F. (2017). Disaster Risk Management Specialist and Trainer. Disaster Management Solutions (DMS) (Pty) Ltd. Personal communication, 28 February 2017.

IWMI. (n.d.). IWMI home page. Available at: http://www.iwmi.cgiar.org Accessed on 27 February 2017.

Lovison, L., Parodi, L., Monett, A., Dueñas, P., Nativi, S., Santoro, M. (2016). A GEOSS Architecture Implementation Pilot Project for Disasters in Chile. Photogrammetric Engineering and Remote Sensing. 82 (2): 79-85. Available at: http://www.sciencedirect.com/science/article/pii/S00991 1121630026X Accessed on 1 March 2017. Science Direct.

Martin, S. (2017). Registered Geoinformation Professional at GeoTerraImage (Pty) Ltd. Personal communication, 3 March 2017.

Mbanjwa, S. (2017). South Africa Department of Environment Affairs: Keynote and session presentations. ICCS5: Innovation in Climate Services and Capacity Building. 28 February to 2 March 2017. Lagoon Beach Hotel, Milnerton, Cape Town.

Mück, M. (2013). Center for Satellite Based Crisis Information. Available at: https://www.zki.dlr.de/project/2312 Accessed on 25 February 2017. German Aerospace Center (DLR): German Remote Sensing Data Center (DFD).

Musango, J. (2017). Professor at University Stellenbosch, School of Public Leadership. Stellenbosch; Personal communication, 23 February 2017.

National Disaster Management Centre (NCDM). (n.d.). NDMC Home page. Available at: http://www.ndmc.gov.za Accessed on 28 February 2017.

NDMC FFGS. (n.d.). FFGS Home page. Available at: Accessed on 27 February 2017.

National Geospatial Information (NGI). (n.d.). South Africa Spatial Data Infrastructure. 
http://www.ngi.gov.za/index.php/what-we-do/sa-spatial Accessed on 9 January 2017.

NOAA. (n.d.). National Ocean Service home page. Available at: http://oceanservice.noaa.gov Accessed on 27 February 2017.

North-West University (n.d.). ACDS home page. Available at: http://www.nwu.ac.za and http://www.acds.co.za Accessed on 27 February 2017.

National Research Foundation (NRF). (n.d). NRF home page. Available at: http://www.nrf.ac.za Accessed on 28 February 2017.

SEAON. (n.d.). SAEON Home page. Available at: http://www.saeon.ac.za Accessed on 28 February 2017.

South African National Biodiversity Institute (SANBI). (2011). National Climate Change Response White Paper.

http://www.sanbi.org/sites/default/files/documents/docu ments/national-climate-change-response-whitepaper.pdf Accessed on 2 October 2015.

SANBI. (n.d.a). SANBI Home Page. Available at: http://www.sanbi.org/ Last accessed on 25 February 2017.

SANBI. (n.d.b). SANBI Infobases. Available at: http://www.sanbi.org/information Last accessed on 25 February 2017.

SANBI. (n.d.c). SANBI BGIS. Available at: http://www.bgis.sanbi.org Last accessed on 25 February 2017.

SANBI. (2017). National Vegetation Map chapters: Available via: http://www.sanbi.org/news/nationalvegetation-map-chapters-available-download at http://bgis.sanbi.org/Projects/Detail/101, however was not able to access the latter at various times between 28 January and 1 March 2017.

SANSA. (n.d.). SANSA home page. Available at: http://www.sansa.org.za Accessed on 27 February 2017.

SASDI. (n.d.) SASDI home page. Available at: http://www.sasdi.org.za Accessed on 10 January 2017.

SASSCAL Rain App. (2016). Available at: https://rain.sasscal.org/ Accessed on 25 February 2017.

SASSCAL Weathernet. (n.d.). Available at: http://www.sasscalweathernet.org/ Accessed on 25 February 2017.

South African Government. (n.d.). Structure and Functions of the South African Government. Available at: http://www.gov.za Ac-cessed on 27 February 2017.

South Africa. (2002). Government Notice: National Disaster Management Act, 2002 (Act No 57 of 2002). Republic of South Africa. Government Printer, Pretoria.

South Africa. (2003). Government Notice: Spatial Data Infrastructure Act, 2003 (Act No 54 of 2003). Republic of South Africa. Gov-ernment Printer, Pretoria.

South Africa. (2005). National Disaster Management Framework. Government Notice 654 of 2005. Republic of South Africa. Gov-ernment Printer, Pretoria.
South Africa. (2013). Government Notice: Spatial Planning and Land Use Management Act, 2013 (Act No 16 of 2013). Republic of South Africa. Government Printer, Pretoria.

Tall, A. (2017). Presentation at side event: What are the prospects for scaling and replicating experimental or pilot climate services in Africa? ICCS5: Innovation in Climate Services and Capacity Building. 28 February to 2 March 2017. Lagoon Beach Hotel, Milnerton, Cape Town .GFCS.

United Nations (UN). (2015). Sustainable Development Goals. Available at: http://www.un.org Last accessed on 27 February 2017.

United Nations (UN-GGIM). (2016). Strategic Framework on Geospatial Information and Services for Disasters: 2016-2030. Working Group on Geospatial Information and Services for Disasters (WG-GISD). The United Nations Committee of Experts on Global Geospatial Information Management (UN-GGIM). United Nations.

United Nations (UNISDR). (2015). Sendai Framework for Disaster Risk Reduction 2015-2013. Available at: http://www.unisdr.org/files/43291_sendaiframeworkfor drren.pdf Accessed various dates between November 2016 and March 2017. United Nations Office for Disaster Risk Reduction.

University of Cape Town (UCT). (n.d.). ACDI home page. Available at: http://acdi.uct.ac.za Accessed on 27 February 2017.

University of the Free State (UFS). (n.d.). DiMTEC home page. Available at: http://www.ufs.ac.za Accessed on 27 February 2017.

University of Pretoria (UP). (n.d.). University of Pretoria Natural Hazard Centre, Africa. Available at: http://www.up.ac.za Accessed on 27 February 2017.

University Stellenbosch. (n.d.). uMama home page. Available at: http://www.sun.ac.za and http://www.umama-africa.com Last accessed on 27 February 2017.

University Stellenbosch. (2016). USAID Awards \$4.1 million to African Universities for Disaster Risk Management. Available at: http://www0.sun.ac.za Accessed on 27 February 2017.

Van Staden, M. (2017). GIS Manager at the South African National Disaster Management Centre, COGTA; Personal communication, 8 March 2017.

Watkiss, P. (2017). Presentation at side event: What are the prospects for scaling and replicating experimental or pilot climate services in Africa? ICCS5: Innovation in Climate Services and Capacity Building. 28 February to 2 March 2017. Lagoon Beach Hotel, Milnerton Cape Town. Paul Watkiss and Associates.

Western Cape Disaster Management Centre (WCDMC). (n.d.). WCDMC home page. Available at http://www/westerncape.gov.za/ Ac-cessed on 28 February 2017. 
Western Cape Government Department of Agriculture. (n.d.). Home page. Available at: http://www.westerncape.gov.za Accessed on 27 February 2017.

World Meteorological Association (WMO). (n.d.). GFCS home page. Available at: http:/www.wmo.int/gfcs/ Accessed on 3 March 2017.

Water Research Commission (WRC). (n.d.). WRC home page. Available at: http://www.wrc.org.za Accessed on 27 February 2017. 